\title{
IS LOW ANTIEPILEPTIC DRUG DOSE EFFECTIVE IN LONG-TERM SEIZURE-FREE PATIENTS?
}

\author{
Tânia A.M.O. Cardoso ${ }^{1}$, Fernando Cendes², Carlos A.M. Guerreiro ${ }^{3}$
}

\begin{abstract}
Objective: To investigate the value of leaving seizure-free patients on low-dose medication. Method: This was an exploratory prospective randomized study conducted at our University Hospital. We evaluated the frequency of seizure recurrence and its risk factors following complete or partial antiepileptic drug (AED) withdrawal in seizure free patients for at least two years with focal, secondarily generalized and undetermined generalized epilepsies. For this reason, patients were divided into two groups: Group 1 (complete AED withdrawal), and Group 2 (partial AED withdrawal). Partial AED withdrawal was established as a reduction of $50 \%$ of the initial dose. Medication was tapered off slowly on both groups. Follow-up period was 24 months. Results: Ninety-four patients were followed up: 45 were assigned to complete (Group 1) AED withdrawal and 49 to partial (Group 2) AED withdrawal. Seizure recurrence frequency after two years follow-up were $34.04 \%$ in group 1 and $32.69 \%$ in Group 2. Survival analysis showed that the probability of remaining seizure free at $6,12,18$ and 24 months after randomization did not differ between the two groups $(p=0.8)$. Group 1: 0.89, $0.80,0.71$ and 0.69 ; group 2: $0.86,0.82,0.75$ and 0.71 . The analysis of risk factors for seizure recurrence showed that more than 10 seizures prior to seizure control was a significant predictive factor for recurrence after AED withdrawal (hazard ratio $=2.73$ ). Conclusion: Leaving seizure free patients on low AED dose did not reduce the risk for seizure recurrence. That is, once the decision of AED withdrawal has been established, it should be complete.
\end{abstract}

KEY WORDS: epilepsy, antiepileptic drug withdrawal, seizure recurrence, prognosis.

Vale a pena manter baixas doses de droga antiepilética em pacientes com epilepsia controlada?

RESUMO - Objetivo: Investigar o valor da manutenção de baixas doses de medicação em pacientes com epilepsia controlada. Método: Trata-se de um estudo prospectivo aleatorizado exploratório, realizado em nosso Hospital Universitário. Nós avaliamos a freqüência de recorrência de crises e os fatores de risco associados após a retirada parcial ou completa da droga antiepiléptica (DAE), em pacientes com crises controladas por pelo menos dois anos. Os pacientes foram divididos em dois grupos: Grupo 1 (retirada completa da DAE) e Grupo 2 (retirada parcial da DAE). Retirada parcial da DAE foi estabelecida como uma redução de $50 \%$ da dose inicial. A medicação foi retirada lentamente nos dois grupos. 0 período de seguimento foi de 24 meses. Resultados: Noventa e quatro pacientes foram seguidos: 45 foram selecionados para a retirada completa (Grupo 1) e 49 para a retirada parcial (Grupo 2). As taxas de recorrência de crises após dois anos de seguimento foram 34,04\% para o Grupo 1 e 32,69\% para o Grupo 2. A análise de sobrevivência mostrou que a probabilidade de permanecer livre de crises aos 6, 12, 18 e 24 meses após a aleatorização não diferiu entre os dois grupos ( $p$ $=0,8$ ). Grupo 1: 0,89, 0,80,0,71 e 0,69; Grupo 2: 0,86, 0,82, 0,75 e 0,71. A análise dos fatores de risco para a recorrência de crises demonstrou que mais que 10 crises antes do controle foi significante para a recorrência após a retirada da DAE (razão de risco $=2,73$ ). Conclusões: A manutenção de baixas doses de medicação em pacientes com epilepsia controlada não reduz o risco de recorrência de crises. Portanto, caso a decisão de retirar a DAE tenha sido estabelecida, a retirada deve ser completa.

PALAVRAS-CHAVE: epilepsia, retirada de droga antiepiléptica, recorrência de crises, prognóstico.

It is widely known that a large majority of epileptic patients benefit from the use of AED, which usually bring about prompt seizure remission. Several studies in newly diagnosed cases of epilepsies, treated with $A E D$, showed one-year remission rates between 65 and $80 \%{ }^{1}$. Retrospective studies based on general populations also demonstrate elevated remission rates in patients who were diagnosed with epilepsy in the past and treated with AED 2,3. Epilepsy, as a chronic condition, generally demands prolonged AED treatment, which may produce toxic effects and risks of morbidity. However, very little is known about the

Department of Neurology, State University of Campinas (UNICAMP), Campinas, SP Brazil: ${ }^{1} \mathrm{MD},{ }^{2}$ Assistent Professor, ${ }^{3}$ Associated Professor.

Received 11 December 2002. Accepted 3 March 2003.

Dr. Carlos A.M. Guerreiro - Department of Neurology, University of Campinas, UNICAMP - P. O. Box 6111 - $13083-970$ Campinas SP Brasil. E-mail: guerreiro@fcm.unicamp.br 
real effect of AED on the evolution of epilepsy. The $A E D$, apparently, do not modify the natural evolution of the disease but seem to simply suppress seizures during a vulnerable period ${ }^{4}$. AED withdrawal is an inevitable question when prolonged remission is achieved. The toxicity of prolonged AED use is the most powerful argument for drug withdrawal ${ }^{5}$. Teratogenic effect in pregnant women and AED interaction with oral contraceptives should be considered as well. Concern about weight gain, compromised osseous metabolism, and reproductive-endocrine disorders in women should also be addressed. ${ }^{6}$. Another important argument in favor of AED interruption is the implicit stigma associated with its use, branding the patient as a chronic disease carrier.

Over the past decades, studies conducted on AED withdrawal after prolonged seizure control in adults and children demonstrated that a great proportion of the patients remained seizure free ${ }^{7}$. Various studies report the evolution of patients with controlled epilepsy after complete AED withdrawal, but no data are available regarding the effectiveness of low AED doses in these patients. Nevertheless, it is not uncommon to observe patients with controlled seizures at "subtherapeutic" AED doses. Some authors state that maybe the seizure threshold increases as the duration of epilepsy increases, modifying minimal therapeutic drug level. This is an important issue, because maintenance of lower AED doses would guarantee seizure control with reduced drug toxicity. Nevertheless, patients would have other benefits such as reduced treatment costs.

The objective of this pilot study is to investigate the value of leaving seizure-free patients on low-dose medication.

\section{METHOD}

This is an exploratory, randomized, prospective study that compares the risk of seizure recurrence after total and $50 \%$ partial AED withdrawal in patients with controlled epilepsy during a follow-up period of two years. This study was conducted at the Neurology Clinic of our University Hospital. The initial evaluation as well as the follow-up was exclusively performed by the first author, at a specific outpatient clinic. The period for patient inclusion extended from January 1991 to November 1995.

Patients included in this study were those who had partial or generalized tonic-clonic seizures (GTCS) and who have been seizure-free for two years or longer. They must have 14 years-old or more and be on monotherapy with AED conventional doses. Epilepsy was defined as the occurrence of two or more unprovoked seizures with at least 24 hours between the seizures ${ }^{8}$. Patients with idiopathic partial and primary generalized epilepsies as well as acute symptomatic and single seizure cases were not included in the study. Patients with confirmed psychiatric diseases and those with non-compliance were excluded.

The decision to withdraw AED was taken after the patient was invited to participate in the study and after thoroughly discussing the risks and benefits with the patient and the family. After the patients had agreed to participate in the study and before randomization, all the patients and/or their families (in the case of patients under 18 years of age) signed informed consents. The Ethic Committee of University of Campinas approved the study.

Patients were then randomly assigned to two groups: Group 1 - gradual and complete withdrawal within six months; Group 2 - partial withdrawal of $50 \%$ of the AED dose in two months. The technique of randomization used was alternating allocation of consecutive patients.

Before initiating withdrawal of the medication, a complete detailed clinical history was obtained in relation to epilepsy, personal and family antecedents, treatments and complementary investigations. All patients were subjected to clinical as well as neurological examinations.

1. Patients and Follow-up - From a total of 136 consecutive patients initially assessed, 117 patients fulfilled the inclusion criteria, agreed to participate in the study and were randomized. A group of 18 patients who were already randomly selected were later excluded because of inclusion errors: 10 patients due to either non-compliance or lost follow-up, two patients who later admitted a seizure control period of less than two years, one patient with primary generalized epilepsy (diagnosed after his inclusion in the study), one patient with a non-epileptic seizure (syncope), one patient had a single seizure with status epilepticus, one patient at withdrawal admitted that he was already on a sub-dose, one patient refused to sign the informed consent and one patient died due to gastro-intestinal cancer. The remaining 99 patients were followed up.

From the 19 patients not included: six of them were already on a subdose and/or reducing AED dose, five patients were concerned about the withdrawal and refuse to participate, four had less than two years of seizure control, one was a chronic alcoholic with seizures due alcohol abstinence, one patient had psychiatric antecedents and probable non-epileptic seizures, one had unclear diagnosis and one had serious medical condition that required postponement of the procedure.

The follow-up period of each patient began on the day the AED withdrawal was initiated. However, as comparative analysis was being conducted, time zero was considered as the time at which both groups reached $50 \%$ of the initial AED dose. From this moment onwards, the groups would differ in relation to interventions and as a result, comparison would be more reliable. The patients were followed up until seizure recurrence or for 24 months after reach $50 \%$ AED dose. Therefore, patients who presented seizure recurrence during withdrawal, while utilizing $75 \%$ of the AED dose were excluded of the comparative analysis. The main purpose was to assess seizure recurrence. 
Five of the 99 patients that initiated the follow-up were excluded from the comparative analysis (two from Group 1 and three from Group 2) because they presented seizure recurrence during withdrawal while utilizing $75 \%$ of the AED dose. Than, the comparative analysis covered a total of 94 patients and none of the patients were lost during the follow- up period of two years.

Clinical characteristics of the patients - The clinical and demographic characteristics of 94 patients included in the comparative analysis were: Group 1 with 45 patients and Group 2 with 49 patients; 44 patients were females $(46.81 \%) ; 74$ patients were white $(78.72 \%)$. The median age when withdrawal was initiated was 30.3 years (minimum $=15$ and maximum $=76$ years), the median age at epilepsy onset was 16.9 years (minimum $=0.1$ and maximum $=62$ years), the median active epileptic duration was 10.7 years (minimum $=0.1$ anad maximum $=40$ years). Seizure control period before withdrawal: 64 patients $(68.09 \%)$ presented two to three years, 17 patients (18.09\%) presented 3 to 4 years and 13 patients $(13.83 \%)$ presented 4 years or more.

Recall visits took place every two months during the withdrawal phase and every four to six months during the follow-up phase, with telephone calls every six months to make sure that information regarding seizure recurrence was reported. All patients were also instructed to phone the physician in case of seizure recurrence. Precise information regarding seizure recurrence and type was obtained through detailed interviews held with the patient and whenever possible with witnesses present.

2. Method and rate of withdrawal - Withdrawal began with a $25 \%$ of the total dose and then $25 \%$ every two months until withdrawal was complete for Group 1 (predicted period of 6 months) and up to $50 \%$ of the initial dose for Group 2 (predicted period of 2 months). According to the commercial preparations available, the real AED dose administered was as close as possible to the calculated dose.

3. Epileptic seizures and syndromes - The seizures were classified according to the revised ILAE Classification of Epileptic Seizures (1981) ${ }^{9}$. Classification of the type of epilepsy was based on the ILAE Classification of Epilepsies and Epileptic Syndromes (1989) ${ }^{10}$. A diagnosis of symptomatic epilepsy was concluded when an etiological factor was clearly recognized or when clinical or imaging signs detected a cerebral lesion that was consistent with a type of epilepsy. The terms cryptogenic epilepsy were used when the etiology was unknown. The supposed localization of an epileptogenic zone was based on seizure semiology as well as electroencephalographic and imaging findings. Patients without unequivocal features of focal or generalized seizures such as those with only GTCS that occurred exclusively while sleeping and without focal findings by clinical, imaging or electroencephalographic tests were classified as undetermined epilepsy $(10,11)$.
Status epilepticus was defined as more than 30 minutes of continuous seizure activity or two or more sequential seizures without full recovery of consciousness between seizures $^{9,12}$.

4. Electroencephalogram (EEG) - Electroencephalograms were obtained in accordance with the international norms related to the "10-20 System" electrode placement and montages recommended by the American EEG Society ${ }^{13}$. The exams were always performed utilizing activation methods (hyperventilation and intermittent photic stimulation) during wakefulness and whenever possible, spontaneous sleep.

The EEG was performed in 88 of the 94 patients during AED withdrawal. Available EEGs performed before AED withdrawal (90/94 patients) and after withdrawal (92/94 patients) were also assessed.

EEGs were qualitatively analyzed by a team of electroencephalographers at the Clinical Neurophysiology Department without previous knowledge about the randomization of AED withdrawal. In the analysis, the EEG results were classified as normal versus abnormal. Abnormal EEG was considered when epileptiform abnormalities and/or focal or diffuse slowing were present.

After AED discontinuation EEG results were assessed. It was considered worsening in EEG pattern when epileptiform activity was registered de novo or when it became abnormal.

5. Family history - Previous family history of epilepsy or an unprovoked single epileptic seizure that occurred in first-degree relatives and/or two or more second or third degree relatives were considered as positive.

6. Imaging exams - A computerized tomography (CT) was performed on all the patients and magnetic resonance imaging (MRI) was performed on 78 patients.

7. Epilepsy severity markers - We tabulated the total number of seizures and number of GTCS before seizure control; duration of active epilepsy (period between the first and last seizure before control); previous unsuccessful attempts at AED withdrawal (excluding abrupt withdrawals); number of AED required in monotherapy to control seizures since the disease onset (to judge effectiveness, adequate doses of AED were utilized for adequate periods); previous history of status epilepticus before withdrawal; maximum seizure frequency before control (Fig. 8 evidencing of the region of the body of an arachnoid granulation evidencing thick bundles of collagen fibers (arrows) associated to thinner bundles (arrows 1). 1100x $\geq 1$ /month and $<1$ /month).

8. AED and serum dosage of AED - The serum dosage of AED was obtained before initiating withdrawal (with a $100 \%$ AED dose) in all but two patients who were on sodium valproate. The serum dosage level before initiating withdrawal did not influence the medical decision concerning withdrawal. 
The results were analyzed utilizing the parameters defined in the literature ${ }^{14}$ in the following therapeutic ranges: Carbamazepine -4 to $12 \mathrm{ug} / \mathrm{ml}$, Phenytoin -10 to 20 $\mathrm{ug} / \mathrm{ml}$ and Phenobarbital - 10 to $40 \mathrm{ug} / \mathrm{ml}$.

Daily AED doses and plasma levels range as follows: carbamazepine 400 to $1400 \mathrm{mg} /$ day (media $=692.7$ ) and $<1.0$ to $12.9 \mathrm{ug} / \mathrm{ml}$ (media $=6.95$ ), phenytoin 200 to 400 $\mathrm{mg} / \mathrm{day}$ (media $=295.8$ ) and $<1.0$ to $37.4 \mathrm{ug} / \mathrm{ml}$ (media $=$ 8.63), phenobarbital 100 to $150 \mathrm{mg} /$ day (media $=101.8$ ) and 1.0 to $34.6 \mathrm{ug} / \mathrm{ml}$ (media $=15.21$ ) and valproate 500 to $1500 \mathrm{mg} /$ day (media $=1000$, only two cases).

9. Summary of the recurrence risk factors - Sex, age at AED withdrawal (up to 30 and above 30 years), age at onset of epilepsy (up to 12 and above 12 years), family history of epilepsy, etiology of epilepsy (localized symptomatic, localized cryptogenic and undetermined), presence of deficits on neurological examination, seizure type (partial or generalized/secondarily generalized), seizure control period (between two to three years and three years or more), EEG, CT, AED used at withdrawal, AED serum level at withdrawal and the epilepsy severity markers.

Statistical analysis - Statistical methods used took into consideration the duration of the follow up period, as it influences the probability of seizure recurrence. Therefore, the survival analysis was utilized to observe seizure recurrence after AED withdrawal. The Kaplan-Meier curves provided a cumulative probability of remaining seizure free (non-recurrence or remission) in relation to time. The univariate and multivariate analysis were applied using the Cox proportional hazard regression model to assess the prognostic factors affecting seizure recurrence ${ }^{15}$.

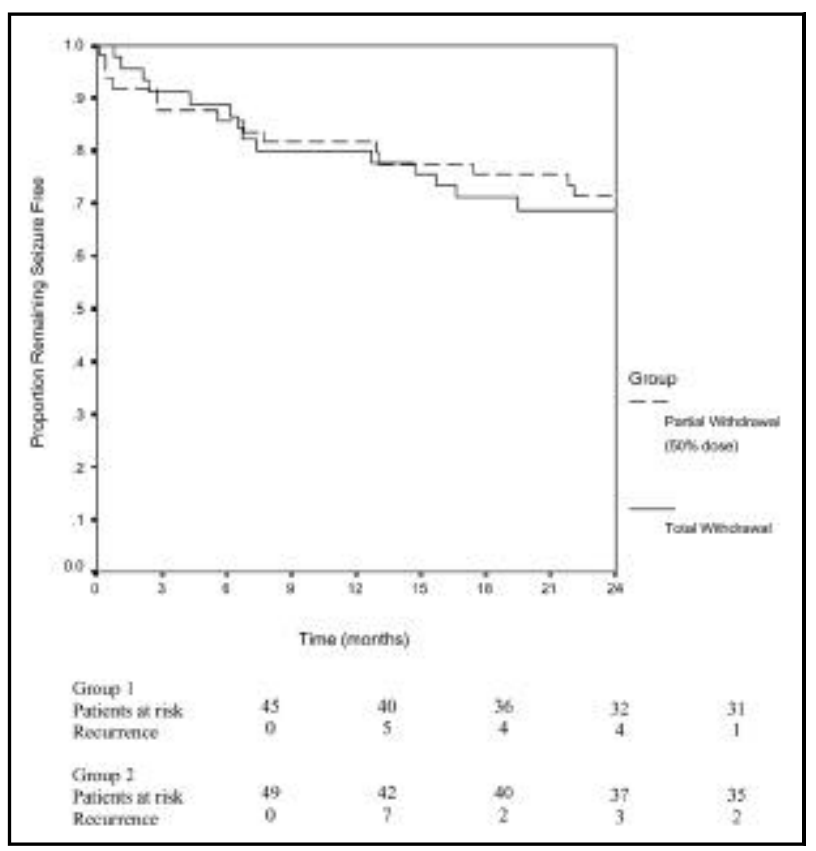

Fig 1. Cumulative probability of remaining seizure free following discontinuation of AED in a 24 months follow-up, in patients with controlled epilepsy: overall recurrence risk - Kaplan-Meier survival curves comparing total with partial $50 \%$ dose.
Table 1. Cumulative probability of remaining seizure free among randomized groups after starting AED withdrawal (Survival analysis).

Survival Probability (Proportion of Remission) after starting AED withdrawal

\begin{tabular}{ccccc}
\hline & 6 months & 12 months & 18 months & 24 months \\
\hline Group 1 & 0.8889 & 0.8000 & 0.7111 & 0.6889 \\
Group 2 & 0.8571 & 0.8163 & 0.7551 & 0.7143 \\
Total & 0.8723 & 0.8085 & 0.7340 & 0.7021 \\
(Group 1+ & & & & \\
Group2) & & & & \\
\hline $\mathrm{p}=0.8067$ & & &
\end{tabular}

\section{RESULTS}

\section{Overall recurrence risk}

During the first two years of follow-up, 16 out of 47 patients in Group 1 (34.04\%) and 17 out of 52 patients in Group 2 (32.69\%) presented seizure recurrence. Two patients from Group 1 and three patients from Group 2 presented recurrence while using $75 \%$ of the initial AED dosage during the first six months of follow-up.

The survival analysis of 94 patients who were subjected to two therapeutic strategies indicating the time dependent cumulative probability of patients remaining seizure free is shown in Figure 1. This cumulative probability of continuing in remission at $6,12,18$ and 24 months after initiating drug withdrawal was $0.89,0.80,0.71,0.69$ for Group 1 and $0.86,0.82,0.75,0.71$ for Group 2 (Table 1).

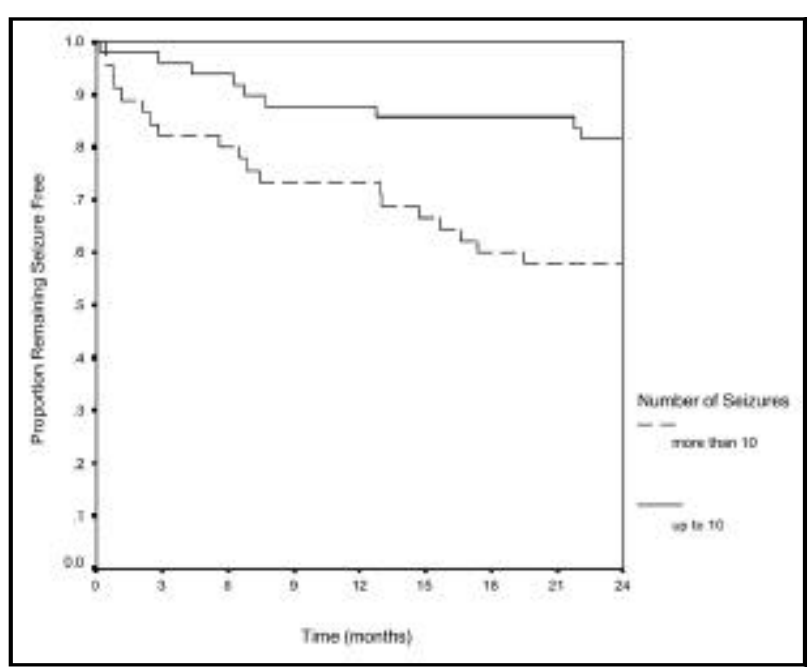

Fig 2. Cumulative probability of remaining seizure free following discontinuation of AED in a 24 months follow-up, in patients with controlled epilepsy: effect of total number of seizures before control on outcome - Kaplan-Meier survival curves comparing patients with up to 10 seizures and with more than 10 seizures before control. 
Table 2. Univariate analysis of risk factors for seizure recurrence after total or partial AED withdrawal - Cox proportional hazards regression model.

\begin{tabular}{|c|c|c|c|c|c|c|c|}
\hline \multirow[b]{2}{*}{ Variables } & \multicolumn{4}{|c|}{ Recurrence } & \multicolumn{2}{|c|}{ Univariate Model } & \multirow[b]{2}{*}{$\mathrm{p}$-value } \\
\hline & Yes & $(\%)$ & No & $(\%)$ & $\begin{array}{l}\text { Hazard } \\
\text { Ratio }\end{array}$ & $\begin{array}{l}\text { 95\% Confidence } \\
\text { Interval }\end{array}$ & \\
\hline \multicolumn{8}{|l|}{ Withdrawal type } \\
\hline Partial withdrawal & 14 & 28.6 & 35 & 71.4 & & & \\
\hline Total withdrawal & 14 & 31.1 & 31 & 68.9 & 1.10 & $(0.52-2.30)$ & 0.8067 \\
\hline \multicolumn{8}{|l|}{ Sex } \\
\hline Female & 16 & 36.4 & 28 & 63.6 & & & \\
\hline Male & 12 & 24.0 & 38 & 76.0 & 0.62 & $(0.29-1.30)$ & 0.2049 \\
\hline \multicolumn{8}{|l|}{ Seizure type } \\
\hline Generalized & 26 & 31.0 & 58 & 69.1 & & & \\
\hline Partial & 2 & 20.0 & 8 & 80.0 & 0.64 & $(0.15-2.70)$ & 0.5453 \\
\hline \multicolumn{8}{|l|}{ Total Number of seizures } \\
\hline Up to 10 & 9 & 18.4 & 40 & 81.6 & & & \\
\hline More than 10 & 19 & 42.2 & 26 & 57.8 & 2.72 & $(1.23-6.01)$ & 0.0137 \\
\hline \multicolumn{8}{|l|}{ Number of GTCS } \\
\hline Up to 10 & 14 & 22.2 & 49 & 77.8 & & & \\
\hline More than 10 & 14 & 45.2 & 17 & 54.8 & 2.43 & $(1.16-5.11)$ & 0.0187 \\
\hline \multicolumn{8}{|l|}{ Neurological Examination } \\
\hline Normal & 26 & 30.2 & 60 & 69.8 & & & \\
\hline Abnormal & 2 & 25.0 & 6 & 75.0 & 0.73 & $(0.17-3.08)$ & 0.6704 \\
\hline \multicolumn{8}{|l|}{$\mathrm{CT}$} \\
\hline Normal & 10 & 24.4 & 31 & 75.6 & & & \\
\hline Abnormal & 18 & 34.0 & 35 & 66.0 & 1.47 & $(0.68-3.18)$ & 0.3301 \\
\hline \multicolumn{8}{|l|}{ EEG before withdrawal } \\
\hline Normal & 13 & 27.7 & 34 & 72.3 & & & \\
\hline Abnormal & 14 & 32.6 & 29 & 67.4 & 1.24 & $(0.59-2.65)$ & 0.5712 \\
\hline \multicolumn{8}{|l|}{ EEG at withdrawal } \\
\hline Normal & 19 & 31.7 & 41 & 68.3 & & & \\
\hline Abnormal & 9 & 32.1 & 19 & 67.9 & 1.09 & $(0.49-2.41)$ & 0.8324 \\
\hline \multicolumn{8}{|l|}{ EEG after withdrawal } \\
\hline Normal & 11 & 22.9 & 37 & 77.1 & & & \\
\hline Abnormal & 17 & 38.6 & 27 & 61.4 & 1.95 & $(0.91-4.17)$ & 0.0841 \\
\hline \multicolumn{8}{|l|}{ Age at epilepsy onset } \\
\hline Up to12 years & 11 & 30.6 & 25 & 69.4 & & & \\
\hline Above 12 years & 17 & 29.3 & 41 & 70.7 & 0.94 & $(0.44-2.00)$ & 0.8614 \\
\hline \multicolumn{8}{|l|}{ Active epilepsy duration } \\
\hline Up to_3 years & 5 & 21.7 & 18 & 78.3 & & & \\
\hline More than 3 years & 23 & 32.4 & 48 & 67.6 & 1.42 & $(0.57-3.49)$ & 0.4512 \\
\hline \multicolumn{8}{|c|}{ N. ${ }^{\circ}$ of AED needed to control seizures } \\
\hline 1 & 14 & 25.9 & 40 & 74.1 & & & \\
\hline 2 or more & 14 & 35.0 & 26 & 65.0 & 1.21 & $(0.57-2.53)$ & 0.6215 \\
\hline \multicolumn{8}{|c|}{ Maximal previous seizure frequency } \\
\hline Up to $1 /$ month & 14 & 25.9 & 40 & 74.1 & & & \\
\hline More than $1 /$ month & 14 & 35.0 & 26 & 65.0 & 1.50 & $(0.72-3.16)$ & 0.2807 \\
\hline
\end{tabular}


Table 2. Continued.

\begin{tabular}{|c|c|c|c|c|c|c|c|}
\hline \multirow[b]{2}{*}{ Variables } & \multicolumn{4}{|c|}{ Recurrence } & \multicolumn{2}{|c|}{ Univariate Model } & \multirow[b]{2}{*}{$\mathrm{p}$-value } \\
\hline & Yes & $(\%)$ & No & $(\%)$ & $\begin{array}{l}\text { Hazard } \\
\text { Ratio }\end{array}$ & $\begin{array}{l}95 \% \text { Confidence } \\
\text { Interval }\end{array}$ & \\
\hline \multicolumn{8}{|c|}{ Previous AED withdrawal attempt } \\
\hline No & 22 & 32.8 & 45 & 67.2 & & & \\
\hline Yes & 6 & 22.2 & 21 & 77.8 & 0.68 & $(0.28-1.68)$ & 0.4073 \\
\hline \multicolumn{8}{|l|}{ Age at AED withdrawal } \\
\hline Up to 30 years & 15 & 73.2 & 41 & 26.8 & & & \\
\hline Above 30 years & 13 & 65.8 & 25 & 34.2 & 1.29 & $(0.62-2.72)$ & 0.4971 \\
\hline \multicolumn{8}{|l|}{ EEG evolution (worse) } \\
\hline No & 18 & 32.1 & 38 & 67.9 & & & \\
\hline Yes & 10 & 33.3 & 20 & 66.7 & 1.02 & $(0.47-2.21)$ & 0.9618 \\
\hline \multicolumn{8}{|c|}{ AED serum level with $100 \%$ dose } \\
\hline Therapeutic range or high & 22 & 34.4 & 42 & 65.6 & & & \\
\hline Low & 5 & 19.2 & 21 & 80.8 & 0.51 & $(0.19-1.35)$ & 0.1747 \\
\hline \multicolumn{8}{|l|}{ Etiology } \\
\hline Cryptogenic Localized & 12 & 30.8 & 27 & 69.2 & & & \\
\hline Symptomatic Localized & 14 & 26.9 & 38 & 73.1 & 0.88 & $(0.41-1.91)$ & 0.7514 \\
\hline Undeterminate & 2 & 66.7 & 1 & 33.3 & & & \\
\hline \multicolumn{8}{|l|}{ Family history of seizures } \\
\hline Negative & 17 & 28.8 & 42 & 71.2 & & & \\
\hline Positive & 11 & 32.4 & 23 & 67.7 & 1.184 & $(0.55-2.53)$ & 0.6631 \\
\hline \multicolumn{8}{|l|}{ Years of seizure control } \\
\hline 2 to 3 years & 19 & 29.7 & 45 & 70.3 & 1.00 & $(0.45-2.22)$ & 0.9951 \\
\hline More than 3 years & 9 & 30.0 & 21 & 70.0 & & & \\
\hline \multicolumn{8}{|l|}{ AED } \\
\hline Phenytoin & 4 & 16.7 & 20 & 83.3 & & & \\
\hline Carbamazepine & 12 & 29.3 & 29 & 70.7 & 1.95 & $(0.63-6.04)$ & 0.2479 \\
\hline Phenobarbital & 11 & 40.7 & 16 & 59.3 & 2.90 & $(0.92-9.12)$ & 0.0683 \\
\hline Valproate & 1 & 50.0 & 1 & 50.0 & - & - & - \\
\hline
\end{tabular}

\section{Risk factors for recurrence}

Univariate Analysis: the analysis of the risk factors for recurrence was performed for the whole population sample. Table 2 presents the univariate analysis of the factors analyzed and their association with a modified risk of recurrence. The variable status epilepticus was excluded from the analysis, as the number of positive cases was small: four positive cases out of a total of 94 cases. After analyzing all the factors, only the number of seizures prior to control presented a correlation with risk of seizure recurrence after AED withdrawal: patients who presented
Table 3. Multivariate analysis of risk factors for seizure recurrence after total or partial AED withdrawal - Cox proportional hazards regression model.

\begin{tabular}{llcl}
\hline \multicolumn{4}{c}{ Multivariate Model } \\
\hline Variable & $\begin{array}{l}\text { Hazard } \\
\text { Ratio }\end{array}$ & $\begin{array}{c}\text { 95\% Confidence } \\
\text { Interval }\end{array}$ & p-value \\
\hline $\begin{array}{l}\text { Total number } \\
\text { of seizures }\end{array}$ & & & \\
Up to 10 & & & \\
More than 10 & 2.73 & $(1.22-6.07)$ & 0.0142 \\
\hline
\end{tabular}


more than 10 seizures before achieving control (19/ $45-42.2 \%$ ) presented a risk 2.72 times greater than those who presented up to 10 seizures $(9 / 49-18.4 \%)$ $(p=0.014$; Table 2). Figure 2 demonstrate the survival curves for accumulated remission probability related to time for patients with up to 10 seizures and for those with more than 10 seizures before control.

Table 2 demonstrates that no significant change occurred regarding the risk of seizure recurrence in relation to the other variables analyzed.

Multivariate Analysis: was performed using the Cox proportional hazards model and those variables with $p<0.20$ in the univariate analysis were also included. After AED withdrawal, only the number of seizures before control once again presented association with seizure recurrence risk $(p=0.014)$ (Table 3).

\section{DISCUSSION}

In this study we found that the frequency of seizure recurrence between patients who underwent partial versus complete AED withdrawal was the same. The overall recurrence risk presented by both groups was similar to that found in other studies and those referred in Berg \& Shinnar's meta-analysis ${ }^{16}: 0.25$ and 0.29 , respectively, one and two years after starting AED withdrawal.

It is interesting to note that two studies that assessed seizure recurrence risk in patients with controlled epilepsy for at least two years maintaining medication have similar results. The MRC Antiepileptic Drug Withdrawal Study Group ${ }^{17}$ reported that the frequency of seizure recurrence in these patients after a two years period was $22 \%$, and Specchio et al. ${ }^{18}$ reported a frequency of $18 \%$ for the same observation period.

Among the risk factors for seizure recurrence, only more than 10 seizures prior to seizure control was significant for recurrence after AED withdrawal at the multivariate analysis. Patients who presented more than 10 seizures before control demonstrated a risk 2.73 fold greater than those who presented up to 10 seizures, as verified by the multivariate analysis. However, it is interesting to note that both the total number of seizures and the number of GTCS affected significantly the risk of seizure recurrence at the univariate analysis. That is because there is a co-linearity between them. This variable, which is an indicator of seizure severity before control, has been shown by other studies to be a predictive factor for seizure recurrence after AED withdrawal ${ }^{19-21}$. Other studies have demonstrated that this factor has shown only a tendency towards significance ${ }^{22,23}$. Moreover, others showed no relationship between number of seizures prior to seizure control and increased recurrence risk for seizure recurrence after discontinuation of $A E D^{24-26}$. However, the importance of these studies might be limited to patients at tertiary epileptic centers, since seizures are easily controlled in a great majority of the patients with recently diagnosed epilepsy?.

EEG result was not a risk factor in our study. Nevertheless, studies often present conflicting results and great variability regarding the EEG characteristics as well as the manner in which these abnormalities are reported and classified. Berg and Shinnar's $\mathrm{s}^{16}$ meta-analysis was used to assess 15 studies and although they were substantially heterogeneous, the relative recurrence risk for patients with abnormal EEG before AED withdrawal was 1.45 fold that of the patients with normal EEG, a small but significant difference. In children, an abnormal EEG before AED withdrawal is an important predictive factor for seizure recurrence. In adults, however, the relationship between abnormal EEG and risk of seizure recurrence has been established in a lesser degree?

We also found no difference in the risk for seizure recurrence when AED withdrawal occurred after a longer period of seizure control: 2-3 years versus > 3 years $(p=0.99)$. This observation was in accordance with most reports in the literature ${ }^{7}$ and suggests that a two-year period of seizure control is sufficient to justify an attempt at AED withdrawal.

The major drawback of our study is the sample size. Since there is no definite data about the risk of seizure recurrence in adults with conventional or low AED dose after a seizure free period of at least two years, it is difficult to establish the exact sample size needed to perform this task. Although a larger sample will be needed to investigate this issue, this would be very difficult to be accomplished without a multicenter study.

It is known that there are individuals who benefit from the maintenance of low AED doses after long periods of seizure freedom; and the maintenance of lower AED doses would reduce drug toxicity, adverse events and treatment costs. However, our study showed that leaving seizure-free patients on low-dose medication did not reduce the risk for seizure recurrence when compared to patients in which the AED was completely withdrawn. That is, once the decision of AED withdrawal has been established, it should be total. This is a preliminary finding, and a larger sample is needed to be assessed in order to confirm these results. 


\section{REFERENCES}

1. Sander JWAS. Some aspects of prognosis in the epilepsies: a review. Epilepsia 1993;34:1007-1016.

2. Annegers JF, Hauser WA, Elveback LR. Remission of seizures and relapse in patients with epilepsy. Epilepsia 1979;20:729-737.

3. Goodridge DMG, Shorvon SD. Epileptic seizures in a population of 6000 , I: Demography, diagnosis and classification, and hole of the hospital services. BMJ 1983;287:641-644.

4. Pedley TA. Discontinuing antiepileptic drugs. N Engl J Med 1988;318:982-984.

5. Reynolds EH. Chronic antiepileptic toxicity: a rewiew. Epilepsia 1975;16:319-352.

6. Morrel M. Managing epilepsy in women across the reproductive cycle. Monograph. A CME Monograph for Neurologists. Secaucus-NJ: Projects in Knowledge, 2001.

7. Shinnar S, Gross-Tsur V. Discontinuing antiepileptic drug therapy. In Wyllie E. Ed. The treatment of epilepsy: principles and practice. 3.Ed. Philadelphia: Lippincott Williams \& Wilkins, 2001:811-819.

8. Hauser WA, Kurland LT. The epidemiology of epilepsy in Rochester, Minnesota, 1935 through 1967. Epilepsia 1975;16:1-66.

9. Commission on classification and terminology of the International League Against Epilepsy. Proposal for revised clinical and eletrencephalographic classification of epileptic seizures. Epilepsia 1981;22:489-501.

10. Commission on classification and terminology of the International League Against Epilepsy. Proposal for revised classification of epilepsies and epileptic syndromes. Epilepsia 1989;30:389-399.

11. Semah F, Picot M-C, Adam C, et al. Is the underlying cause of epilepsy a major prognostic factor for recurrence? Neurology 1998;51:1256-1262.

12. Treatment of convulsive status epilepticus: recommendations of the Epilepsy Foundation of America's Working Group on Status Epilepticus. JAMA 1993;270:854-859.

13. American Eletroencephalographic Society Guidelines in EEG and Evoked Potentials: Guideline seven: A proposal for standard montages to be used in clinical EEG. J Clin Neurophysiol 1986;3(Suppl 1):26-33.
14. Levy RH, Mattson RH, Meldrum BS (ed.). Antiepileptic drugs. 4.Ed. New York: Raven Press, 1995

15. Collet D. Modeling survival data in medical research. London: Chapman \& Hall, 1994.

16. Berg AT, Shinnar S. Relapse following discontinuaton of antiepileptic drugs: a meta-analysis. Neurology 1994;44:601-608.

17. Medical Research Council Antiepileptic Drug Withdrawal Study Group. Prognostic index for recurrence of seizures after remission of epilepsy. BMJ 1993;306:1374-1378.

18. Specchio LM, Tramacere L, Neve A La, Beghi E. Discontinuing antiepileptic drugs in patients who are seizure free on monotherapy. J Neurol Neurosurg Psychiatry 2002;72:22-25.

19. Emerson R, D'Souza BJ, Vining EP, et al. Stopping medication in children with epilepsy: predictors of outcome. N Engl J Med 1981;304:1125-1129.

20. Callaghan N, Garrett A, Goggin T. Withdrawal of anticonvulsant drugs in patients free of seizure for two years: a prospective study. N Engl J Med 1988;318:942-946.

21. Gherpelli JLD, Kok F, dal Forno S, Elkis LC, Lefevre BHW, Diament AJ. Discontinuing medication in epileptic children: a study of risk factors related to recurrence. Epilepsia 1992;33:681-686.

22. Juul-Jensen P. Frequency of recurrence after discontinuance of anticonvulsant therapy in patients with epileptic seizures. Epilepsia 1964;5:352-363.

23. Ehrhardt F, Forsythe WI. Prognosis after grand mal seizures: a study of 187 children with three-year remissions. Dev Med Child Neuro 1989;3:633-639.

24. Shinnar S, Vining EPG, Melits ED, et al. Discontinuing antiepileptic medication in children with epilepsy after two years without seizures: a prospective study. N Engl J Med 1985;313:976-980.

25. Shinnar S, Berg AT, Moshé S, et al. Discontinuing antiepileptic drugs in children with epilepsy: a prospective study. Ann Neurol 1994;35:534-545.

26. Tennison M, Greenwood R, Lewis D, Thorn M. Discontinuing antiepileptic drugs in children with epilepsy: a comparison of a sixweek and a nine-month taper period. N Engl J Med 1994;330:1407-1410. 